Article

\title{
A Point of View on New Education for Smart Citizenship
}

\author{
Cristina Martelli \\ Department of Statistics, Informatics and Applications, University of Florence, 50134 Firenze, Italy; \\ cristina.martelli@unifi.it; Tel.: +39-329-360-3327
}

Academic Editor: Dino Giuli

Received: 21 September 2016; Accepted: 17 January 2017; Published: 1 February 2017

\begin{abstract}
Smart cities and intelligent communities have an ever-growing demand for specialized smart services, applications, and research-driven innovation. Knowledge of users' profiles, behavior, and preferences are a potentially dangerous side effect of smart services. Citizens are usually not aware of the knowledge bases generated by the IT services they use: this dimension of the contemporary and digital era sheds new light on the elements concerning the concept of citizenship itself, as it affects dimensions like freedom and privacy. This paper addresses this issue from an education system perspective, and advances a non-technical methodology for being aware and recognizing knowledge bases generated by user-service interaction. Starting from narratives, developed in natural language by unskilled smart service users about their experience, the proposed method advances an original methodology, which is identified in the conceptual models derived from these narratives, a bridge towards a deeper understanding of the informative implications of their behavior. The proposal; which is iterative and scalable; has been tested on the field and some examples of lesson contents are presented and discussed.
\end{abstract}

Keywords: smart education; social innovation; statistical information systems; data reuse; transparency

\section{Introduction}

New technologies have a huge impact on social life [1,2], changing (i) the quality of personal relationships [3,4]; (ii) the concept of proximity [5]; (iii) the idea of authority; (iv) privacy; (v)liberty; (vi) economy [6]; and (vii) democracy.

Many authors have reflected on the impact of new technologies on personal lives and on the concept of being a citizen: as new technologies are always information-rooted, considerations have been made in terms of the right of being skilled enough to cope with modernity $[7,8]$ and on the respect of rights in the digital society.

The role of smart technologies in social participation [9-11] has also been widely explored and discussed, as well as how they improve and empower citizens' initiative, proactivity, and involvement efforts.

The aim of this paper is to address the issue of "being an active and conscious citizen" (in all the accepted meanings of this expression) from a different perspective. Information technologies use and create data spaces: a plurality of repositories and databases keep citizens' memories, creating a sort of digital territory that any modern citizen is obliged to inhabit. Among traditional citizenship dimensions, new rights, linked to these new digital territories, have to be granted: awareness of potential dangers is the main element to achieve, as citizens usually fail to recognize the smart service costs, mainly focused on privacy and freedom.

The underlying idea is that citizens cannot be fully integrated into a modern society without a clear image of their position and role in digital spaces. In this sense, when asking or using smart 
services and intelligent territories, citizens ought to be aware (i) of the processes (mainly informative and induced by the services they use) involving communities and individuals; and (ii) of their real body boundaries in this unprecedented information territory. The effects of the presence of a person in digital territories may, in fact, deeply impact their lives, relationships and personal security.

The deep gap existing between stakeholders' languages may hamper these goals. Technicians in charge of the design and construction of smart infrastructure and services are (and often are pleased to be) beyond the comprehension of other citizens: a consequence is that an increasing component of common experiences is outside the citizens' control, vigilance, and awareness. In this work, we advance the idea that natural language, when linked to technology basics, may be a powerful instrument for achieving social consciousness and broad recognition of technology costs and benefits. This point is hardly surprising as linguistic competency is traditionally a core capability for full citizenship [12,13]: in this paper, this idea is developed and updated for the smart citizens' benefit.

In this perspective, an original educational proposal is advanced and some experiences discussed. The aim is to achieve a methodology, based on conceptual modeling, for addressing new citizenship issues, adopting different and converging perspectives: narrations, data, IT, and measures. The final goal is to induce in young students (and in their teachers) the idea that, in order to be an active citizen in modern society, all of these skills must act together, sharing a common language [14].

The paper is organized as follows: after a brief focus on the complexity paradigm, the concept of multidimensional citizenship in a knowledge space is discussed. With this in mind, the paper analyses the strategic role of natural language and conceptual modeling and presents some applications and lesson examples.

\section{Education to Complexity}

What do we mean by smart citizenship [15]? Is it about enjoying smart territory benefits or demanding innovative services? Does it concern drawbacks and dangers for freedom and privacy [16]? In all cases it involves being skilled enough to cope with modernity and new social instruments: education to complexity is paramount.

In a traditional context, citizens are usually able to recognize their position in a hierarchy (social or economic) and in a community. Nowadays, the challenge is to recognize this position in a network, as a node connected through a plurality of relations and processes, feedbacks and back interactions.

Before reflecting on what being a citizen in a complex context means, it is worth focusing on complexity and its consequences in social life.

According to Barabási conceptualization and language [17], a complex network is not just a matter of interconnected agents: complex systems display several organizing principles, which are, at some levels, encoded in their topology.

\subsection{Small World}

Small world propriety means that, despite their size, in most networks there is a relatively short path between any two nodes. The distance between two nodes is defined as the number of edges along the shortest connecting path: the most popular small world expression [18] is the "six degrees of separation" concept, proposed in 1967 by the social psychologist Stanley Milgram.

Small world property has inspired sociologists and politicians and it has often been declined in terms of interdependency and multiculturalism: in this paper, we would like to re-think it in terms of the citizens' right to short distances to services and information. Communities are nowadays experiencing an unprecedented situation: they are inside a highly interconnected external environment, even if the governance rules are still grounded on authority and accountability principles, often organized in terms of hierarchies. The gap between the hierarchy of responsibilities and the network of information is difficult to understand and accept. 
The complexity of modern citizenship challenges calls for an original tradeoff between the capacity to exert full authority and power (through hierarchies) and the acknowledgement that only a network system of competencies, vigilance, and trust can assure transparency and democracy.

\subsection{Clustering}

A common property of complex networks is an inherent tendency to clustering, quantified by the clustering coefficient [19]: in most real networks, the clustering coefficient is typically much larger than it is in a random network of an equal number of nodes and edges.

Social networks provide practical evidence of this point. It is worth considering how clustering occurrences often happen without the cluster participants' knowledge: this is the case of those driven by marketing, political, or consensus reasons.

\subsection{Degree Distribution}

Not all nodes in a network have the same number of edges. Usually in a random graph, as the edges are placed randomly, the majority of nodes have approximately the same degree and their distribution $P(k)$, which gives rise to the probability that a randomly selected node has exactly $k$ edges, is a Poisson distribution. Empirical results show that for complex networks, the degree distribution significantly deviates from a Poisson distribution. Such networks are called scale-free [20]. A scale-free network originates when a node, having to establish a new association, prefers to link itself with a node already characterized by many connections, contributing to an exponential growth of its connections inside the network: in this way the functional form of $P(k)$ deviates from the Poisson distribution of $P(k)$ expected for a random graph.

A social consequence is that complex networks, also thanks to innovative technologies, indicate new leadership modalities sometimes outside the citizens' awareness or control.

\section{Being a Citizen in a Smart and Complex Environment}

Complex networks have strong implications in many domains, and there are many cases in which recognizing a system as such (from information, to epidemiology, to social systems, to communities) allows for having a deeper insight into its properties, potentialities, and behaviors [21], empowering, in this way, citizens' awareness. Adopting a network and complexity perspective for reflecting on citizenship may provide new insights in modern societies.

Citizenship has been one main narrative in describing construction strategies of political and social arrangements in modern societies [22]: complexity may have a deep impact on this.

After the 1949 Marshall's Cambridge Lecture [23], citizenship has been theorized not only as a legal and political status, but also as a social status [24], thus gaining a multidimensional character: the expansion of individual and collective rights, in fact, is traditionally attached to the status of citizen.

In modern societies, the process of rights claiming, which is a traditional active citizenship expression, is usually mediated by IT systems. Citizens ask for efficiency, accessibility, and performance; they demand an evolutive environment, able to recover from errors and disservices, oriented to ever-growing service provisions.

In smart communities, therefore, persons have a two-fold citizenship experience: on one side, the level of their rights recognition is satisfied as never before, on the other, services in support of rights compliance, being IT mediated, generate complex data networks, the digital territories previously outlined. The concepts of community and citizenship are deeply involved and changed: traditionally, a community has been modeled as a political or institutional unit, a set of personal and empirical relationships, or on the basis of the geographical spaces where lives happen. Nowadays a community is also a linguistic object, in which every citizen is both author and content of different narrations. When integrated together, they form the overall information system [25-27], which, according to the complexity paradigm previously discussed, could be extraordinarily more informative than the sum of its components. 
The modern communities and citizenship dimensions previously outlined, fit very well with the smart city concept: despite the fact that the term "smart city" has become more and more widespread, its sense, definition and dimensions are not always clear $[28,29]$. As any city may be conceived in terms of relations and territories [30], in this paper smart city will be conceptualized as a particular context, capable of learning from feedbacks and reacting to its inhabitants needs: a territory in which information is used to shape relations useful for adapting services to its stakeholders' exigencies and rights.

Following the complex paradigm outlined above, we can see how smartness falls within this frame.

Being highly connected environments, smart cities present a network structure in which the encoded topological properties previously discussed are usually true: at what level is a citizen aware of being in a small world? Is he/she aware of the existence of a plurality of path to reach targets, information, institutions? Are citizens conscious of the existence of hubs? What kind of legitimacy do they have? In accordance with which process does a network edge become a hub?

In this perspective, the educational proposal for smart citizenship will be advanced and discussed [31].

\subsection{Natural Language and Conceptual Modeling in Support of Citizenship}

As previously outlined, it is widely acknowledged that living in a complex environment may provide advantages and potentialities. A question arises: are citizens also able to recognize and evaluate risks and costs connected to the services they are asking for?

Usually communities find a trade-off between benefits and costs linked to rights acknowledgment: for instance, in traditional social debates, there may be conflict about the costs of services delivery and their distribution. Nowadays we also have to take into account those linked to proper and legitimate management of the complex digital spaces generated by the acknowledged services. The risks associated with abuse are also to be considered.

A smart citizen, aware of being an element of a more general narration, must be provided with skills and instruments to shape digital spaces according to their visions, projects, rights protection.

As with any citizenship dimension, this awareness has to be granted to everyone, regardless of personal technical skills: in this paper, natural language and conceptualizations are the required competences: we are dealing with non-technical assets widely used by IT professionals to model and build smart services. The challenge is to also restore them to unskilled citizens in order to empower them and allow them to verify and discuss potential smart service risks for individuals and communities.

\subsubsection{Natural Language}

The first tool in support of smart citizenship is natural language: its role in information system design and construction is known and is related to careful and active listening to the users' needs and requirements.

It is not surprising that narrations are so strategic in both developing and using an information system: Jerome Bruner [32], for instance, has argued that one of the ways in which people understand their world is through the "narrative mode" of thought, which is concerned with human wants, needs, and goals.

In formal information system development, the production and collection of narrations and storytelling corresponds to the part of the design process in which the users' needs and requirements (along with their service vision) are collected and analyzed. It is worth noticing that this aspect in information system development is closer to traditional active citizenship: it concerns speaking about needs and the contexts and conditions for meeting them.

Information systems are usually developed in line with the methodology sketched in the following image: the boxes with red borders have, to a certain extent, been developed in natural language and, if properly arranged, they may even be up to non-skilled citizens. 
Speaking of public services, for example, initialization could be a political phase in which citizen involvement is usually very high. System design may include dominion-experts: media and public opinion may demand information feedback. The figure shows that due to language and technical barriers, development and implementation are the only processes totally outside the citizens' comprehension.

\subsubsection{Conceptual Models}

The second tool is conceptual modeling. Any information system $[33,34]$ is based on its conceptual model, produced on the basis of collected narrations and stakeholders' requirements.

The role of conceptual modeling in information system development is widely known: the value of conceptual models lies in their ability to capture the relevant knowledge about a domain, facilitating the engagement of involved stakeholders and supporting the reciprocal comprehension of users and designers.

Any real world narration is often translatable in a conceptual model, describing the semantics of the organization and representing assertions about its nature. Relations between ideas, images, or words are represented as well. Conceptual models may have a graphical representation, a map, in which concepts are usually enclosed in circles or boxes, and connecting lines between two concepts specify their relationships.

Conceptual models do not have any IT implications and support mutual comprehension between different languages and technical cultures: in other words, they cannot be considered a merely technological phase (even if they are compulsory in any information system design), as they are linked with the capability of properly describing and defining a problematic area.

The passage from narrations to conceptual models may be performed at different formality levels: in the educational experiences described and discussed in this paper the one closest to the natural language level has been chosen.

System designers use different modeling methodologies for (i) data (entity relationships, object oriented); (ii) processes (Idef0, FRAM); and (iii) interfaces (UML use cases). These approaches are all non-technical and natural language-based, and they are intended to bridge the gap between dominion experts and system developers.

It is always possible to harmonize these models: in the educational proposal, for instance, starting from a description of reality under the user services perspective, we intend to induce knowledge on the data system and on the processes, which generate and use these data.

\subsection{Natural Language, Conceptual Models, and Data Spaces: A Bridge between System Users and Providers}

In this paper, we advance the proposal that when a citizen, using the natural language, is able to recognize a service conceptual model, he/she is also capable of identifying databases, information repositories, informative potentialities as well as linking conditions with other sources: in this way, the digital territory created by the services used begins to take shape.

In this methodological proposal, conceptual models are adopted as an instrument per se, for their explanatory potentialities and their ability to orient unskilled citizens in digital territories. In this perspective, the adopted methodology relies on the use of conceptual mappings [35,36] as a support for education $[37,38]$ to improve a meaningful understanding of the materials studied.

In this approach, concept maps met the need to explicitly show how new concepts and propositions were integrated into the learner's cognitive structure, helping students learn how to learn, capture explicit and tacit knowledge held by experts, assist in the design of instruction, facilitate creative work in every discipline, and facilitate improvement of management and marketing methods.

This proposal actualizes a pioneering use of conceptual mappings [39] and, in this perspective, it does not use conceptual models towards any form of operationalization, but only as an asset in support of comprehension and learning. An original methodological update to this consolidated educational perspective, is given by the fact that, in this case, conceptual modeling is specifically 
addressed to reconstruct and understand an IT service structure by its users' view, with the explicit objective of also learning about the potentialities and risks for privacy, freedom and full active citizenship expression.

A potential drawback is given by the fact that, usually, IT service conceptual models are not available for their users, who only approach them through their interfaces. In approach of this paper, we advance the proposal that this informative gap is bridged using the users' experiences and views developed in natural language as a source for a reverse conceptual modeling.

Citizens require services: their requests, expressed in natural language, are the basis for the new system structure and architecture. When constructed, citizens use the system and obtain the services requested without knowing how it has been built.

They are, in any case, able to describe the delivered services and what the system does: anyone is able to describe the experience of paying with a credit card, using an app to get a service, passing in a video-surveilled street. On the bases of these narrations, it is possible to derive and re-model a system conceptual model draft, useful for the citizens, to gain a clearer view of the digital space created by the services they use.

Moving from interfaces to system architecture and code is not an original approach and it is a classic example of reverse engineering. Citizenship empowerment does not need this technical specification level: it could be enough to broadly recognize the model on which the system architecture is based in its most abstract and general form.

Neither is the idea of using natural language to understand complex organization new [40]; it has quite a long tradition starting from problems of strategic management in complex environments. With respect to these early applications, technology has made important advances, even if the basic approach is still very similar: natural language is a useful modeling tool as it is rich enough to cope with the complexity of organizations.

To support these points, the following picture illustrates a very common situation: an institution wants to provide services to support a problematic area. In this perspective, information systems designers and producers build a problem/solution conceptual model, on the basis of which they create the system.

Citizens, as system users, are represented in the model: to provide the services, their data may be collected and integrated with other sources. They use the system through dedicated interfaces and often interfaces are their only perspective; the picture shows how a simplified system conceptual model draft may be derived from the users' point of view.

The users' conceptual model will not necessarily be the same as the one developed by system designers. It will be less detailed and the result of the joint efforts of different users profiles (illustrated in the picture with different colors), but it will still provide a deeper insight into the system's informative structure. Citizens will be more skilled in recognizing the data territory generated by their service usage.

The chart discussed and presented in Figure 1 has now been completed with the reverse modeling actions performed by citizens.

The following Table 1 summarizes the citizens' role in the different phases of an IT service development.

They are not condemned to transfer their sovereignty to technology: the Table 1 shows all the phases in which they could be actively involved.

Citizens (Figure 2) have several cards to play in order to achieve control and transparency, even in smart and intelligent communities, from the very beginning of the IT processes when they may claim participation in new service modeling, to the usage phase (Figure 3) in which they must be more skilled and conscious in order to be vigilant and critical of the effective costs of smart services. 


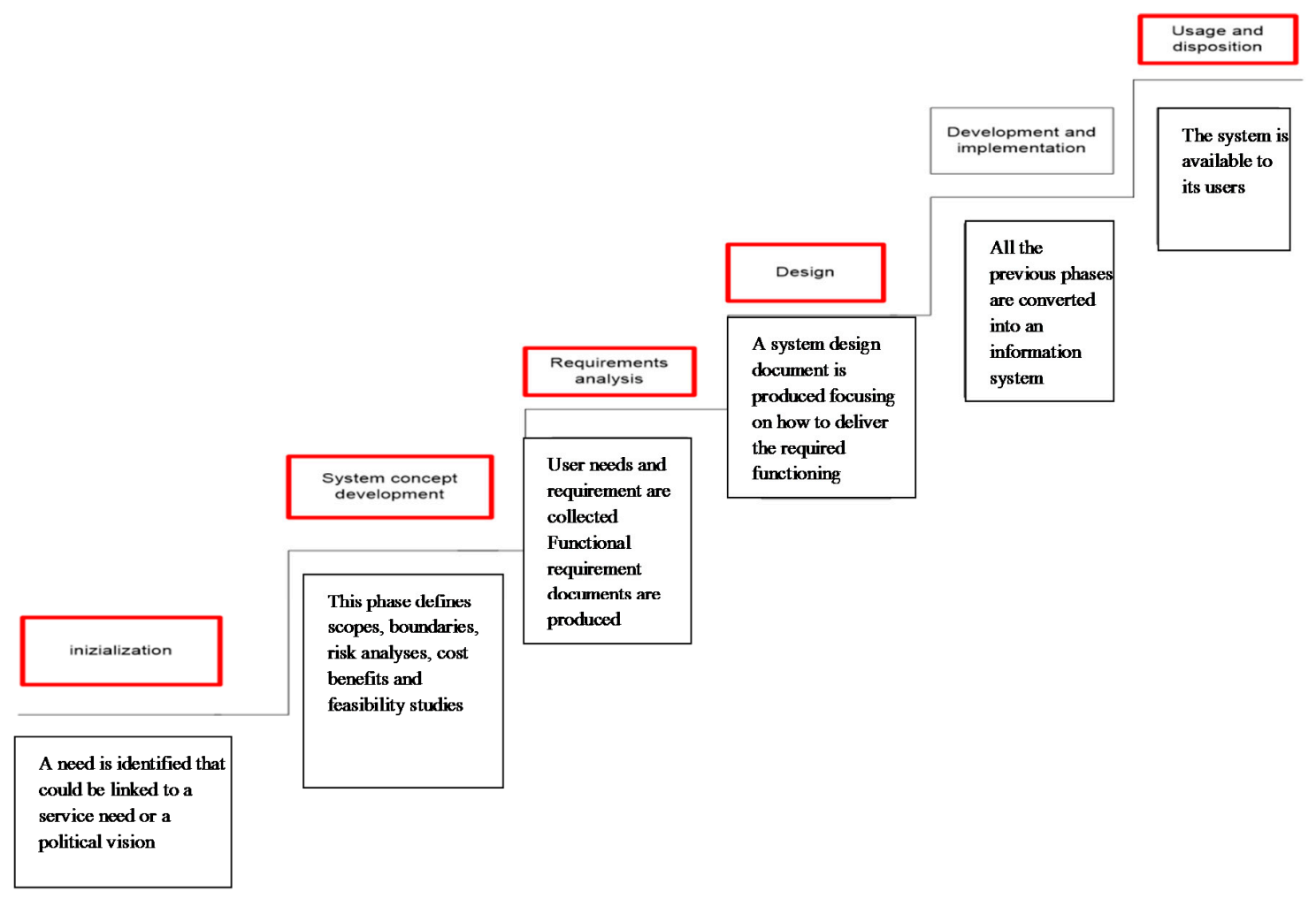

Figure 1. Natural language in the information system-developing scheme. With red borders are all of the phases affected by natural language.

Table 1. Role of citizens.

\begin{tabular}{ccc}
\hline Phase & Role & Process \\
\hline Political decision on rights and services & active & Action on vision promotion and choice \\
\hline Problematic area and description of & active & Citizens describe their needs and requirements \\
\cline { 2 - 3 } services & passive & System designers are collecting and organizing the narrations \\
\hline $\begin{array}{c}\text { Conceptual modeling of services } \\
\text { Construction of services }\end{array}$ & $\begin{array}{c}\text { passive } \\
\text { absent }\end{array}$ & Citizens are modeled \\
Service usage & active & Repositories for citizens' data are constructed \\
& passive & The service is used and the right is granted \\
& & Data on citizen are collected, reused, integrated \\
\hline
\end{tabular}

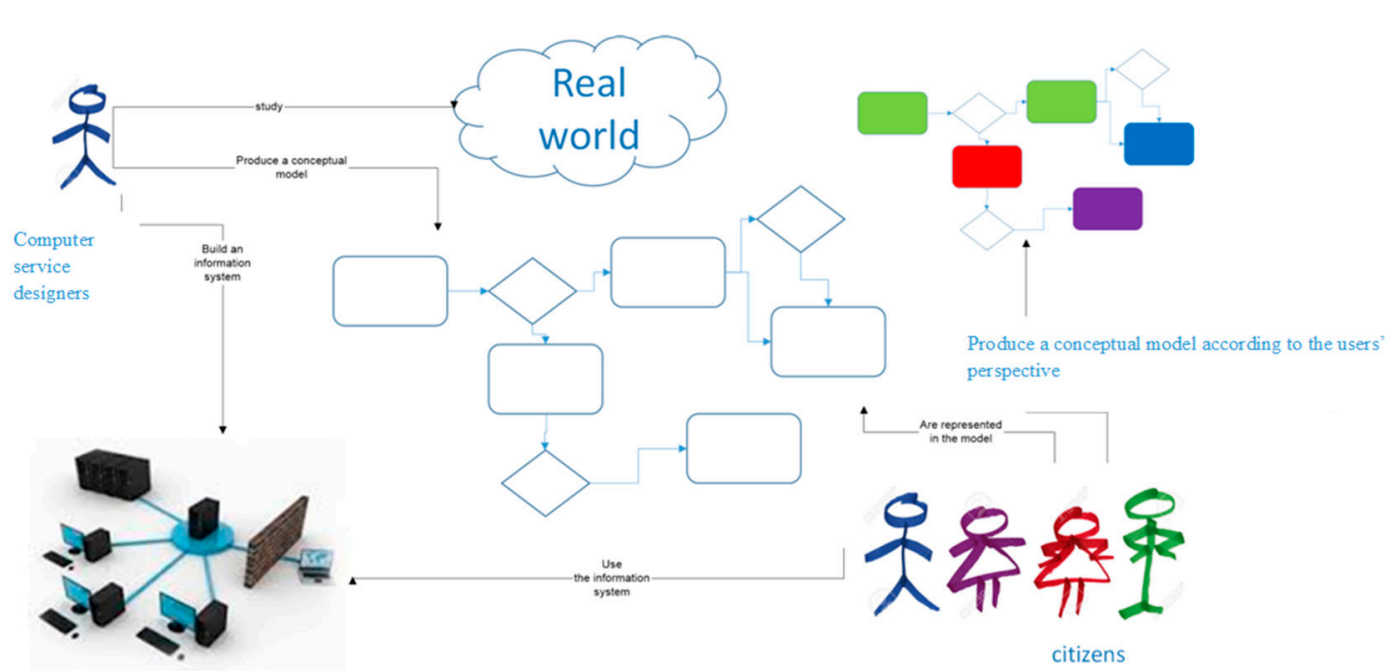

Figure 2. Smart services conceptual models as per the users' perspective. 


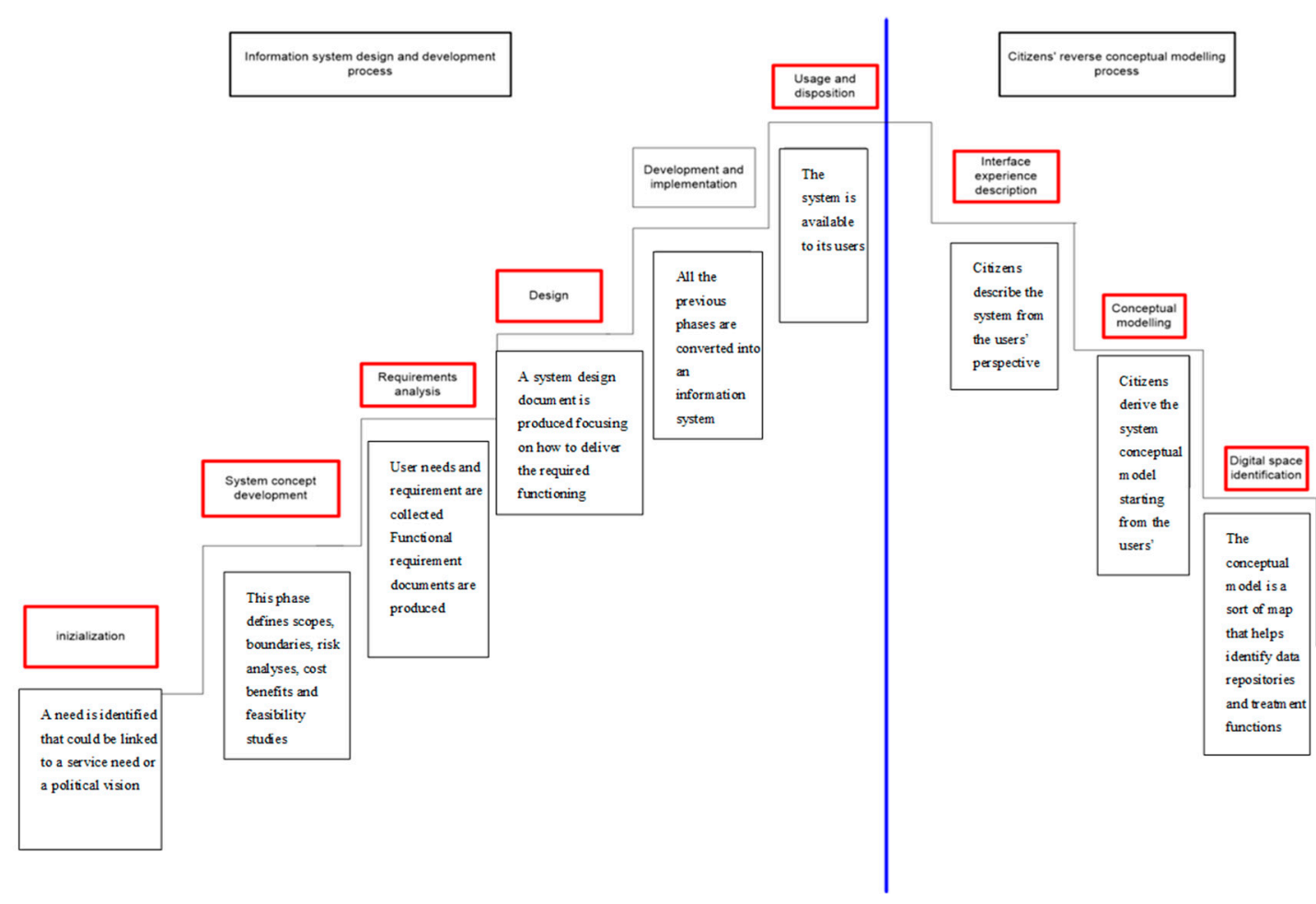

Figure 3. Citizens' reverse conceptual modeling process.

\section{Smart Citizenship: Proposed Guidelines for the New Education Approach}

The topics, previously discussed, have been developed in an educational proposal. Following are the didactical approach and the presentation of the experiences.

\subsection{Making Teachers Work Together}

To cope with new citizenship challenges, the educational system usually provides partial answers. Humanities teachers, for instance, could focus on laws and on the trade-off between people's rights to services and privacy. They could stimulate their students to extend to smart cities the attention usually reserved for press freedom and media propriety. IT teachers could focus on the technological aspects of instruments and services, possibly targeting innovation. Math and statistics teachers could focus on indicators and data analysis. All of these approaches may help, however they are narrow and deal with single issues.

If citizens are required to adapt to complexity, educational systems have to overcome the frequent lack of communication between subjects and disciplines. The objective is to identify a common ground to which every educational stakeholder contributes with specific languages and competencies for overall system comprehension. In line with the above, the required common ground is a conceptual model and the instrument is natural language.

\section{Unifying Subjects}

Bridging the gap due to different languages, sectors and disciplines begins at school: the proposed educational methodology intends to support the co-working of teachers of different disciplines.

Often, in traditional education (Figure 4), the main focus is to ensure disciplinary consistency in terms of coherence, timing, and sequencing of the subject contents. The following picture shows this situation, in which subject outcomes are largely independent. 


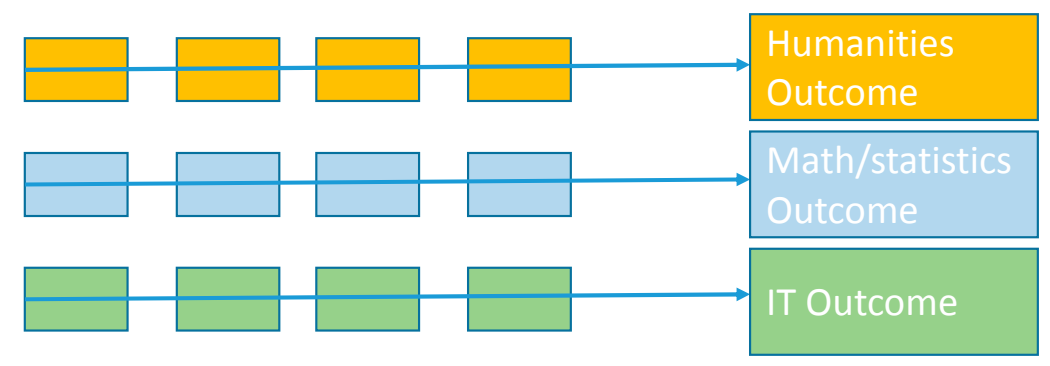

Figure 4. Traditional disciplinary content delivery.

It is widely known [41] that interdisciplinarity increases student engagement and helps them develop their cognitive abilities. "If establishing student learning outcomes for disciplinary courses and programs is hard, it may be even harder to achieve for interdisciplinary courses and programs where there is less agreement about what interdisciplinarity is, what outcomes should be assessed" [42].

The following chart illustrates the recommended teaching framework, in which learning outcomes are in part attributable to specific discipline objectives and, in part, to a more general and interdisciplinary vision.

The joint reference to the same conceptual model enhances parallel integration.

The following diagram shows how the interdisciplinary reference to the same conceptual model helps in bridging subject languages.

\subsection{The Method}

The proposed educational methodology starts with identification of a problematic area, which will be addressed by the joint effort of the different disciplines involved. On the basis of this choice, the following steps will be performed:

- Natural language reality description

- Transformation of this narrative into a set of short phrases (subject, verb, and predicate)

- Transformation of actors (the nouns in the narrative) into nodes

- Transformation of processes (the verbs in the narrative) into relationships

- Production of a graphical representation of this set of nodes and links

- Connection of node and relationship to existing data sets

- Analysis and description of the situation under investigation through quantitative and qualitative approaches.

The following Table 2 highlights the contribution of the disciplines and subjects involved:

Table 2. Disciplinary contributions and their outcomes.

\begin{tabular}{|c|c|c|}
\hline Subject & Action & Result \\
\hline \multirow{3}{*}{ Humanities } & Narration production & Texts \\
\hline & Linguistic analysis & Conceptual model \\
\hline & Conceptual model critical analysis & Informative potentialities and drawbacks \\
\hline \multirow{3}{*}{$\begin{array}{l}\text { Computer } \\
\text { science }\end{array}$} & Data base design and conceptual model & Hypothesis of data structure \\
\hline & Database construction & database \\
\hline & Tech innovation & New sources, sensors, internet of things \\
\hline \multirow{2}{*}{$\begin{array}{l}\text { Math and } \\
\text { statistics }\end{array}$} & Production of indicator suited to the conceptual model & \multirow{2}{*}{$\begin{array}{l}\text { Quantitative description of the } \\
\text { problematic area }\end{array}$} \\
\hline & Data analysis based on the data collected by the service & \\
\hline Humanities & Learning from data New insight into problems & \\
\hline
\end{tabular}


The educational approach illustrated in the table is recursive and not sequential: Phase and roles may also be proposed in parallel to enhance the students' attitude to network reasoning.

\subsubsection{The Role of Humanities Teachers}

Humanities teachers do not normally perceive a specific role in technical education. In this approach, they make a major contribution as they are in charge of the narrative conceptualization.

After having chosen a particular topic, students, supported by their humanities teachers, produce a short paper describing, in natural language, a problematic area, typically a smart service.

To convert this narrative into a conceptual model, humanities teachers show how to transform a text into series of subject-predicate-object expressions, similar to classical conceptual modeling approaches such as entity-relationship or class diagrams. The texts, once conceptualized (i.e., with the entity/relationship approach), become maps and are available for a non-linear reading. While the original paper is made for linear reading, (left to right, start to finish), the maps can be navigated, like a hypertext: the sense is equivalent, the reading modalities are different. By working on the conceptual model, students are now able to explore the system's informative potentialities and to understand what happens when conceptual model elements are filled with data.

It must be noted that subject-predicate-object expressions allow for introducing, (when appropriate for the students age and level), elements of semantic and linguistic structural analysis that may be reused by math teachers (first order logic) and IT (semantic web).

\subsubsection{The Role of Computer Science Teachers}

Computer science teachers contribute to the program by introducing database elements, in compliance with the conceptual model. They discuss with the students the characteristics of the smart service data repositories, and check the availability of form of data restitution, such as open data or linked data.

They reflect on the technological strategies and implications of data linkage.

Sensors, the Internet of Things, and other innovative sources are presented and their role in the conceptual model is discussed.

Starting from the subject-predicate-object expressions produced with humanities teachers, if appropriate for the students' level, they could introduce semantic web elements as well as first-order logic elements together with math and statistics teachers. This aspect is very important as it introduces elements of logical inference on data, semantic web and big data. These elements, returned to the humanities teachers, are an interesting incentive to reflect on social consequences of the use of collected data, according to the structural approach discussed above.

\subsubsection{The Role of Statistics and Math Teachers}

A complex network contains topological properties that math teachers may present and discuss: the most important is the presence of clusters. Other data analysis aspects, in compliance with students' educational level, may also be introduced.

Statistical analysis results, once returned to the humanities teachers, may stimulate further reflections, in the perspective of the recursive process outlined in the previous paragraphs.

\subsubsection{The Joint Role of All Teachers}

Working on the same conceptual model to analyze the digital space is a good strategy for bridging different subjects. The aspects that may be addressed in a joint mode include:

- Linkage strategies, potentialities, and drawbacks between different sources and databases;

- The role of standard administration language in representing complex social networks;

- Grammar and first-order logic. 
The approach previously discussed may be iterated, oriented, and investigated. The following diagram, which has been adapted from [41], reinstates the contents of Table 2 and shows a sort of spiral process [43] that involves different subjects and teachers.

The diagram shows how the problem is addressed by iterating the same methodology at different complexity levels.

The urgency of overcoming singularities in education in order to address knowledge production is obviously not new: this paper proposal has some similarities with the answer advanced by structuralism in the educational field. In that perspective, the concept of profession itself (such as the one of the teachers involved in Figures 5-7) has been deconstructed and reconceptualised as a field [44], assuming a role not far from the conceptual model: a common ground which is functional both to specialist insights and integrated judgments.

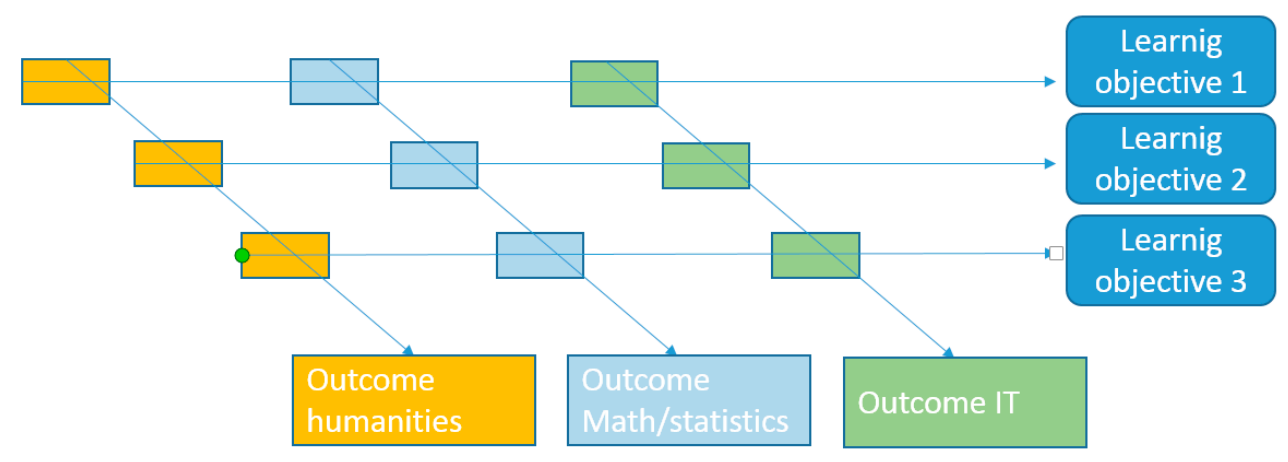

Figure 5. Interdisciplinary content delivery.

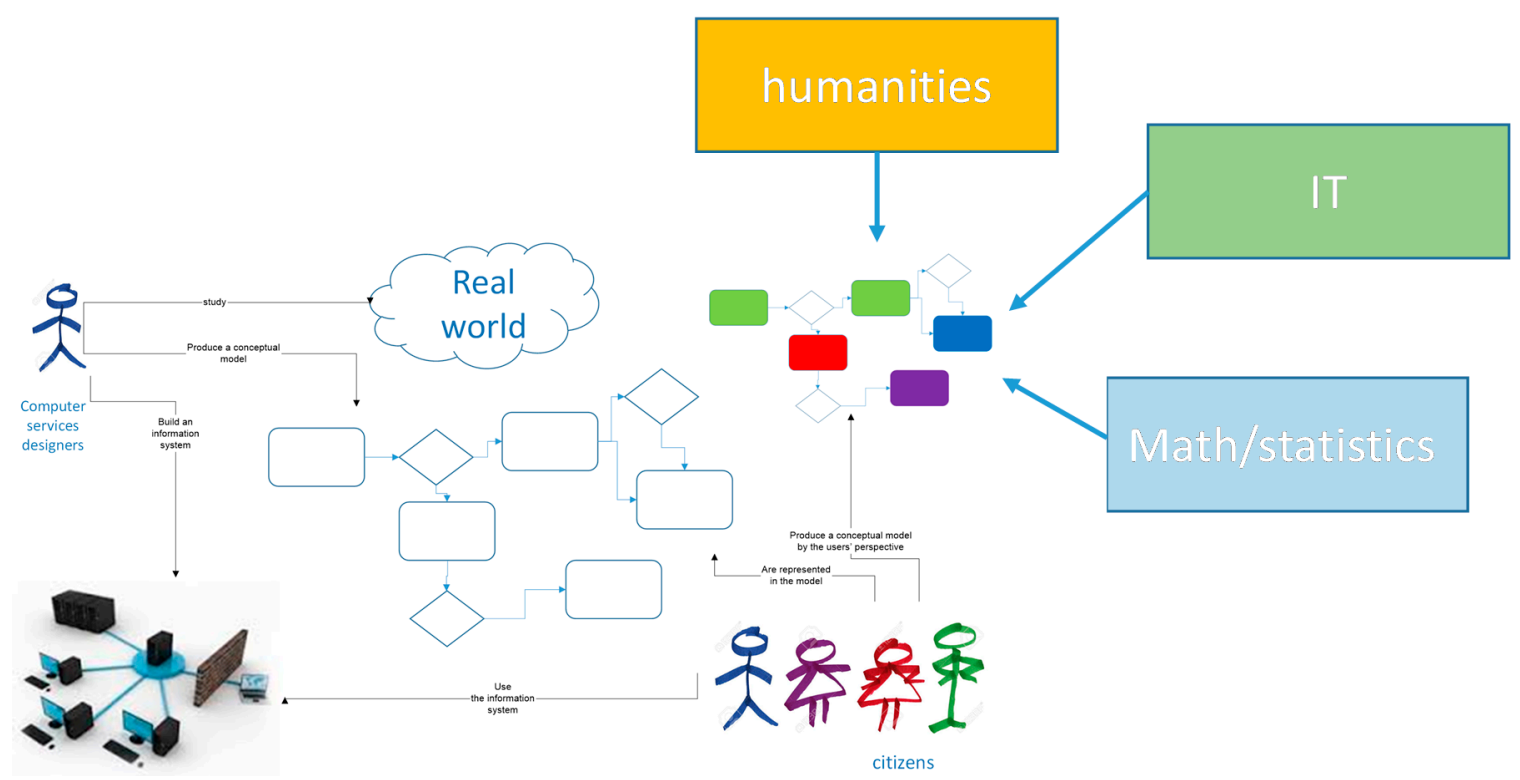

Figure 6. The contribution of conceptual models to an interdisciplinary education approach. 


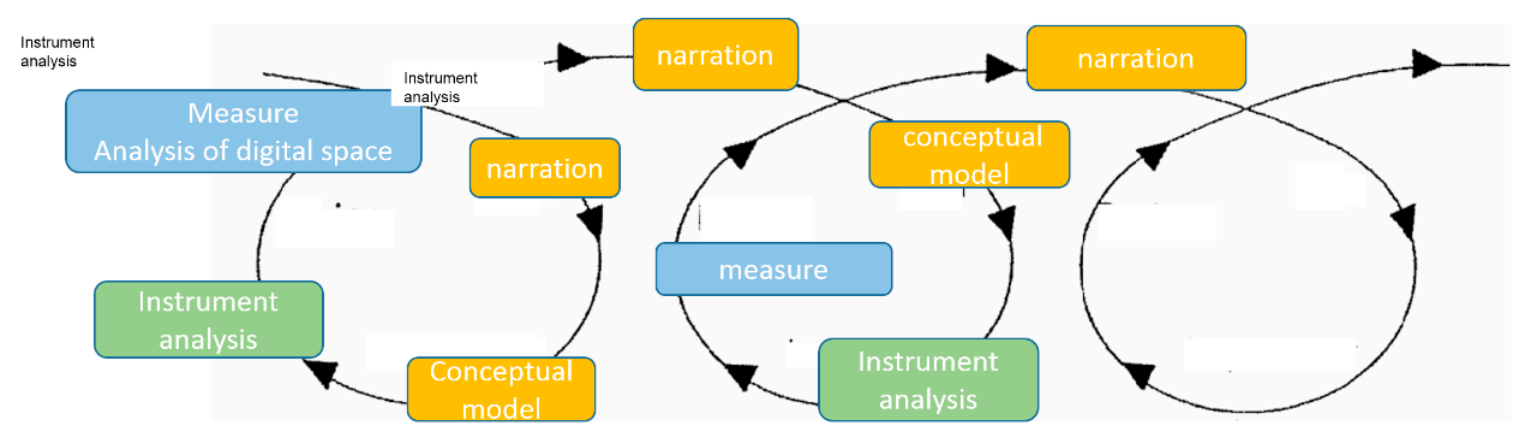

Figure 7. The iterative structure of the proposed methodology.

\subsubsection{Towards a Revised Structuralist Approach?}

It is not a coincidence that the concepts of conceptual model, the object of this proposal, and the one of field advanced by the structuralist approach are so close: underlying them both is the idea that a specific domain, like the digital space generated by smart services, may be understood mainly by means of a structure modeled on language.

Surrounding the idea of the sign and structure, structuralism developed the idea that everything that is acquired, transmitted, and shared is fused in a system that can be formalized as signs. The idea is, therefore, to analyze cultural reality as a language, or a system of signs. The sign, in turn, cannot be defined in an isolated manner. Its existence is relational. The sign's existence derives from the structure of the system, in which it is a knot or a point in the network.

In fact, structuralism [45] affirms that "elements of human culture must be understood in terms of their relationship with a larger, overarching system or structure. It works to uncover the structures that underlie all the things that humans do, think, perceive, and feel". According to Blackburn [46] nothing is intelligible "except through its interrelations. These relations constitute a structure, and behind local variations in the surface phenomena there are constant laws of abstract culture". Caution must be exercised when recognizing these parallels: nevertheless, with the structuralist and post-structuralist writers [47], the proposed educational approach is oriented to emphasize [48] the constitution of subjects and subjective experiences through discursive practices really related to structural signification. The post-structural framework, in particular, shows a high concern with language, its role in human praxis and the effects of narrations on praxis.

Structuralism has often been criticized for being unhistorical and favoring deterministic structural forces over the ability of individual people to act. These critical remarks were made before smart innovation and big data: nowadays they assume new relevance.

In a smart environment, the structure underlying the services (which are in turn the product of a narration) generates digital spaces on which postulations and deductions may automatically be performed. On this basis, private or public institutions may make decisions regarding citizens: this is what is actually happening in a semantic web fed by data generated by smart services. Traditional dichotomies of representation/reality or subjectivism/objectivism are probably overcome in smart territories: education has to address these new forms of knowledge in human praxis to protect social inclusion, and to tackle class reproduction and hierarchies of power, the opposite of the complex environment outlined at the beginning of this paper.

\subsubsection{An Educational Scalable Approach}

Scalability is an important dimension for an educational proposal addressing citizenship empowerment: scalability means that the approach may be adopted at different ages and carrier student phases by students, teachers, and normal citizens. The methodology remains the same.

The proposed approach has been tested in different ways: experiments have been performed with high school students, undergraduates, and graduates. Specific training courses have been proposed 
to teachers to help them to take advantage of the opportunities provided by the methodology: apart from differences in age and cultural level, the method was applied in the same way. This aspect has made cooperation possible among different groups as well as bridging the gap between different school levels.

\subsection{Heuristic Experiences of the New Educational Approach}

In the following, some of the examples proposed to students and teachers are presented and discussed.

\subsubsection{Shopping with a Fidelity Card}

One of the first topics proposed to students and teachers was entitled "What kind of information is generated by the use of a shopping fidelity card?"

Large retail sectors often propose fidelity cards to support loyalty programs. In marketing, a loyalty card identifies the cardholder as a member of a loyalty program. By presenting this card, purchasers usually earn the right either to a discount on the current purchase, or to an accumulation of points to be used for future purchases.

Figure 8 shows, as an example of the class work, one of the conceptual models produced on the basis of the narrations of the experience of the students as fidelity card users: the conceptual model produced allowed the students (16-18 years old) to examine loyalty program privacy concerns. In particular, humanities teachers discussed the informative implications in providing information when applying for cards, on family composition, profession, and personal preferences.

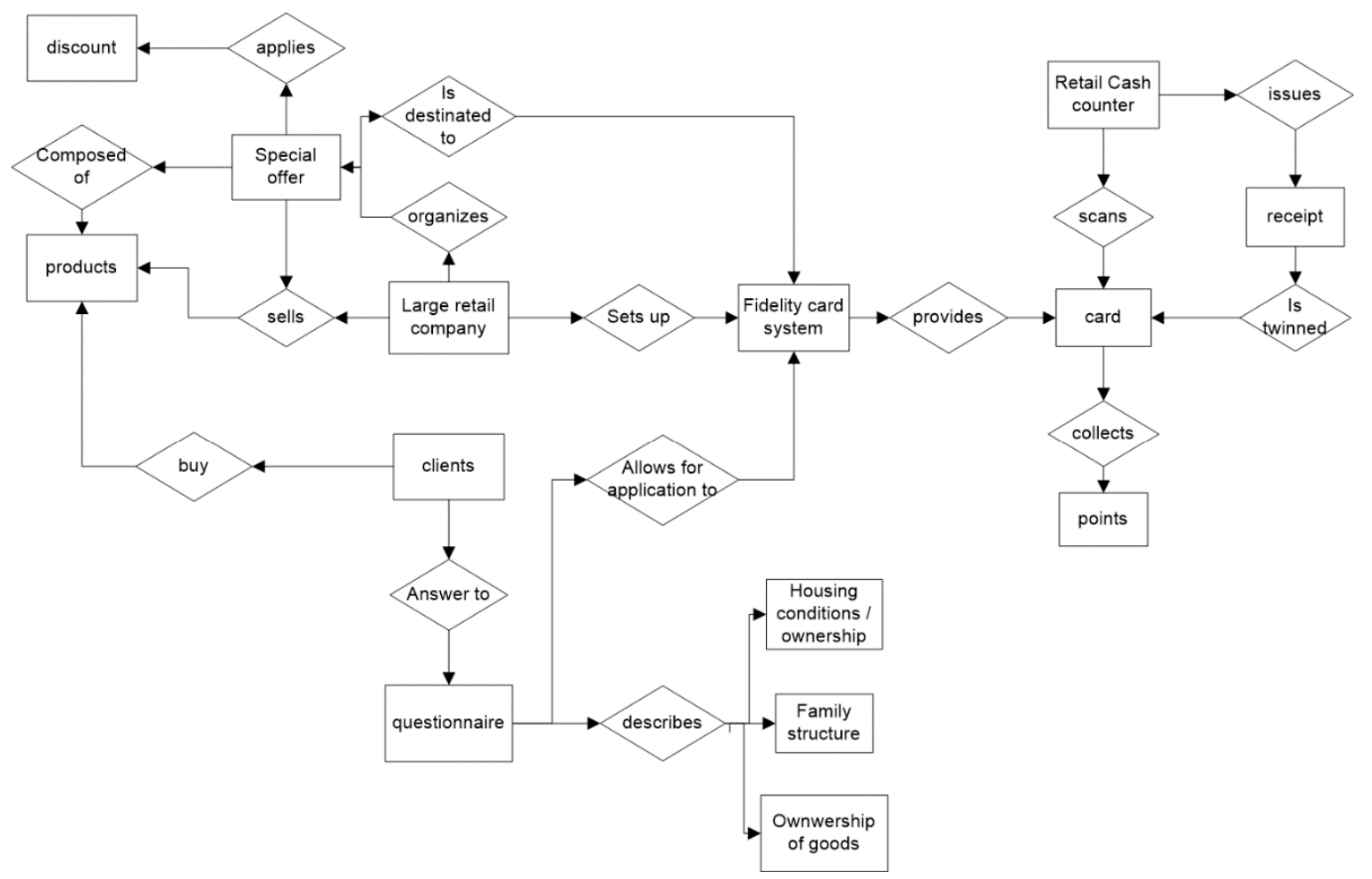

Figure 8. Using a fidelity card: the conceptual model.

The students also reflected on the fact that data could be available at disaggregated levels, even if stores usually apply agreements (typically non-disclosure) concerning customer privacy.

Companies, for instance, may use the information they gather to see to what extent they can modify consumer behavior. Some uses of shopping information are innocuous, but what if a company decides to sell or share personal data like the type of newspaper bought or regarding alcohol purchases? 
In addition, how does one cope with aggressive marketing strategies, made possible by the joint knowledge of personal information and purchasing preferences?

Moreover, the conceptual modeling, allowing a nonlinear narration reading and a full exploration of the problematic area, helped in reflecting on the importance of a thorough reading of the privacy policies attached to shopping cards.

In this specific example, the model was produced by the class transforming the original narration into a list of short phrases made up of subjects, verbs (transitive, wherever possible) and objects. A simple semantic check was carried out to avoid synonyms and fuzzy concepts. The result was translated in the map.

In the educational program proposed, the conceptual model was also used by statistics and math teachers to introduce the indicators produced to sustain marketing policies and to profile purchasers' preferences. For the conceptual map elements, a reflection was stimulated on pertinent measures: different analytical perspectives were proposed and discussed. For instance: what kind of indicators can optimize the offer in relation to the demographic and social profile of cards owners? At what rate are specific goods bought by a certain purchaser cluster?

This further consideration allowed the class to reflect on the perspective, offered by the system, of verifying the correctness and accuracy of the original narrative, as the indicators may offer the chance to check the original assumptions. This is particularly important for reflecting on the importance of institutional statistical communication protocols in a transparency perspective.

\subsubsection{Microchip Trash Collector in Support of Garbage Sorting}

If in the example previously discussed, focus was placed on the relationships between private companies and their clients, a further example was provided on issues arising from the relationships with public service providers.

The students: (i) narrate; (ii) conceptualize; (iii) discuss; and (iv) measure and identify data concerning garbage-sorting policies.

Many communities adopt waste sorting policies in order to minimize residues and pollution. There is a wide consensus around these policies, but some issues regarding privacy may arise.

Adopting the same methodology described above, the students described their experience with regard to garbage sorting. They were then required to discuss and conceptualize some of the approaches used to verify the effective sorting practice implemented by families and citizens. In particular, they were required to model the situations in which the garbage can is identifiable. The model navigation exercise focused on the level of private information that could be derived from garbage inspection. The case in which only the penalized inspection results are recorded was modeled and discussed.

\subsubsection{The Role of Standard Administration Language in Generating Complex Social Networks}

In this lesson students were asked to identify potential data sources to fill and instancialize their conceptual models: this part is usually up to IT teachers. On this occasion the students also reflected on the importance of assuring a standard language in public administration. Government policy implementation is often hierarchically organized to ensure responsibility and accountability: services often involve several public bodies.

The diagram on the left (Figure 9) represents a service delivery structure: more specifically, the lesson focused on the administrative procedures following a work accident. The red elements represent, in the example, the management of workers' hospitalization and, on a completely different branch, the management office of legal affairs.

Students were asked to reflect on the importance of adopting the same administrative language in the red spots: a homogeneous language transforms the organizational hierarchy into an information network, characterized by the small-world property. The data collected in the two institutions are linkable and a knowledge network is generated. The system is able to connect legal and health elements 
and can teach more about causes, consequences, and responsibilities. Students reflected on the fact that administrative dialects may hamper data-mapping in the problematic area conceptual model and be a serious obstacle to transparency.
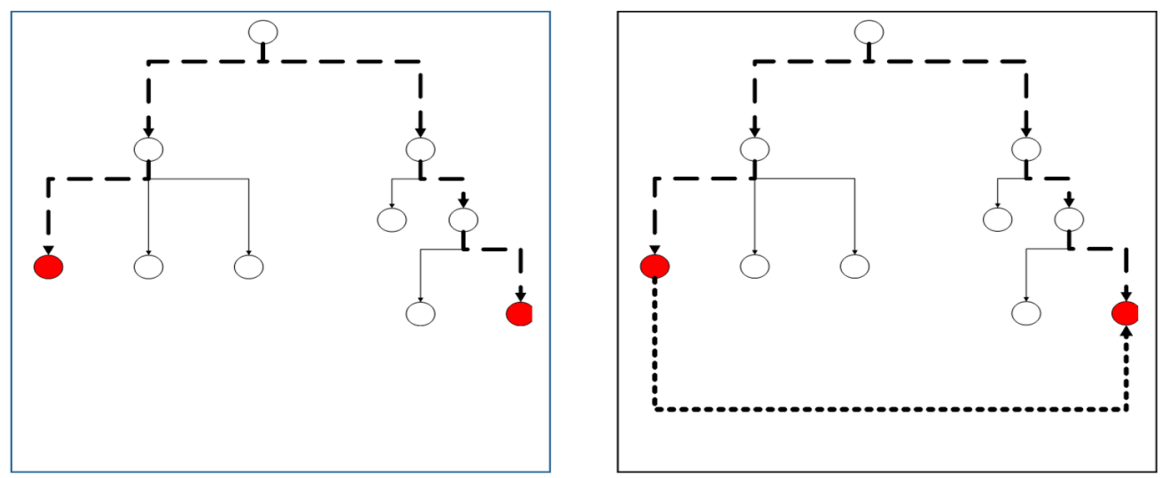

Figure 9. From the hierarchy of responsibilities to the knowledge network.

\section{Final Remarks}

The ever-growing demand for specialized smart services may have potentially dangerous side effects on freedom, privacy and, ultimately, on the concept itself of citizenship and democracy: with respect to this unprecedented situation there is a lack of awareness and knowledge that the education system ought to address, providing cultural assets, and empowering methods and attitudes.

Not an easy challenge, as it involves competencies and skills, which are often narrow and deal only with single issues: humanities, IT, math, and statistics teachers could stimulate and inform their students. However, if citizens are required to adapt to complexity, educational systems have to overcome the lack of communication between subjects and disciplines. The objective is to identify a common ground to which every educational stakeholder contributes with specific languages and competencies for overall comprehension.

This paper advances an educational proposal rooted on conceptual models of the users' experience, which are presented and taught not as the imperative prerequisite for information system operationalization, but as a general and non-technical skill to allow citizens to recognize, discuss and evaluate smart service informative structures.

In this perspective, conceptual models go beyond the IT area and become a crosscutting subject that bridges the gap between languages, sectors and disciplines, supporting the co-working of teachers of different disciplines.

Several examples of lessons are presented and discussed in this paper. The lectures were proposed to classes differing in age and level: the didactic methodology remained the same and was adapted to the students' age and profile with deeper reflections and insights.

In all the situations experienced, the students were able to formulate original ideas and reflections on the potential costs of the citizens' right to avail of smart and intelligent services, using the conceptual models produced as a map to be explored, such as unwanted connections with data sources outside the analyzed smart service, for instance.

Beyond the promising results achieved, a major critical factor may be attributed to the teachers' specific sensibility and preparation on the topic: for this reason, the didactical proposals have to be formulated in a two-step structure: an action addressing educators (together with proper supporting material) and a specific step targeting the students.

It is a complex educational goal: the successfully perceived outcomes of such heuristic experiences indicate further improvement and development directions and motivate us to work out a systematic approach for application of the proposed education guidelines, as well as for its effective evaluation and validation. 
Conflicts of Interest: The author declares no conflict of interest.

\section{References}

1. Bargh, J.A.; McKenna, K.Y. The Internet and social life. Annu. Rev. Psychol. 2004, 55, 573-590. [CrossRef] [PubMed]

2. Nam, T.; Pardo, T.A. Conceptualizing Smart City with Dimensions of Technology, People, and Institutions. In Proceedings of the 12th Annual International Digital Government Research Conference: Digital Government Innovation in Challenging Times, College Park, MD, USA, 12-15 June 2011; pp. 282-291.

3. Hirsch, E.; Silverstone, R. Consuming Technologies: Media and Information in Domestic Spaces; Routledge: Abingdon-on-Thames, UK, 2003.

4. Murthy, D. Digital ethnography an examination of the use of new technologies for social research. Sociology 2008, 42, 837-855. [CrossRef]

5. Kraut, R.E.; Fussell, S.R.; Brennan, S.E.; Siegel, J. Understanding effects of proximity on collaboration: Implications for technologies to support remote collaborative work. Distrib. Work 2002, 1, 137-162.

6. Trainor, K.J.; Andzulis, J.M.; Rapp, A.; Agnihotri, R. Social media technology usage and customer relationship performance: A capabilities-based examination of social CRM. J. Bus. Res. 2014, 67, 1201-1208. [CrossRef]

7. Jarvis, P. Democracy, Lifelong Learning and the Learning Society: Active Citizenship in a Late Modern Age; Routledge: Abingdon-on-Thames, UK, 2008.

8. Turner, B.S. Outline of a Theory of Citizenship. Sociology 1990, 24, 189-217. [CrossRef]

9. Audigier, F. Basic Concepts and Core Competencies for Education for Democratic Citizenship; Council of Europe: Strasbourg, France, 2000.

10. Rheingold, H. Smart MOBS: The Next Social Revolution; Basic Books: New York, NY, USA, 2007.

11. Gaonkar, S.; Li, J.; Choudhury, R.R.; Cox, L.; Schmidt, A. Micro-blog: Sharing and Querying Content through Mobile Phones and Social Participation. In Proceedings of the 6th international conference on Mobile systems, applications, and Services, Breckenridge, CO, USA, 17-20 June 2008.

12. Palen, L.; Anderson, K.M.; Mark, J.; Martin, J.; Sicker, D.; Palmer, M.; Grunwald, D. A Vision for Technology-Mediated Support for Public Participation \& Assistance in Mass Emergencies and Disasters. In Proceedings of the 2010 ACM-BCS Visions of Computer Science Conference, Edinburgh, UK, 13-16 April 2010.

13. Haste, H. Constructing the citizen. Political Psychol. 2004, 25, 413-439. [CrossRef]

14. Bennett, W.L.; Welles, C.; Rank, A. Young citizens and civic learning: Two paradigms of citizenship in the digital age. Citizensh. Stud. 2009, 13, 105-120. [CrossRef]

15. Mossberger, K.; Tolbert, C.J.; McNeal, R.S. Digital Citizenship: The Internet, Society, and Participation; MIT Press: Cambridge, MA, USA, 2007.

16. Bovens, M. Information rights: Citizenship in the information society. J. Political Philos. 2002, 10, 317-341. [CrossRef]

17. Albert, R.; Barabási, A.L. Statistical mechanics of complex networks. Rev. Mod. Phys. 2002, 74, 47. [CrossRef]

18. Milgram, S. The small world problem. Psychol. Today 1967, 2, 60-67.

19. Watts, D.J.; Strogatz, S.H. Collective dynamics of 'small-world' networks. Nature 1998, 393, 440-442. [CrossRef] [PubMed]

20. Barabási, A.L.; Albert, R. Emergence of scaling in random networks. Science 1999, 286, 509-512. [PubMed]

21. Fogelman-Soulié, F. Evolving Networks. In Mining Massive Data Sets for Security: Advances in Data Mining, Search, Social Networks and Text. Mining, and Their Applications to Security; IOS Press: Amsterdam, The Netherlands, 2008; p. 19.

22. Janoski, T. Conflict, Citizenship and Civil Society. Contemp. Sociol. J. Rev. 2011, 40, 151-153. [CrossRef]

23. Turner, B.S. TH Marshall, social rights and English national identity: Thinking Citizenship Series. Citizensh. Stud. 2009, 13, 65-73. [CrossRef]

24. Marshall, T.H. Citizenship and Social Class; Cambridge University Press: Cambridge, UK, 1950; Volume 11.

25. Agranoff, R. Inside collaborative networks: Ten lessons for public managers. Public Adm. Rev. 2006, 66, 56-65. [CrossRef]

26. Börzel, T.A. Organizing Babylon. On the different conceptions of policy networks. Public Adm. 1998, 76, 253-273. [CrossRef] 
27. Macklin, T.; Jenket, P. Achieving Cross-Domain Collaboration. In RTO IST Symposium on Coalition C4ISR Architectures and Information Exchange Capabilities; NATO: Hague, The Netherlands, 2004.

28. Chourabi, H.; Nam, T.; Walker, S.; Gil-Garcia, J.R.; Mellouli, S.; Nahon, K.; Scholl, H.J. Understanding Smart Cities: An Integrative Framework. In Proceedings of the 2012 45th Hawaii International Conference on System Science (HICSS), Maui, HI, USA, 4-7 January 2012.

29. Schaffers, H.; Komninos, N.; Pallot, M.; Trousse, B.; Nilsson, M.; Oliveira, A. Smart Cities and the Future Internet: Towards Cooperation Frameworks for Open Innovation. In The Future Internet Assembly; Springer: Berlin/Heidelberg, Germany, 2011.

30. McCann, E.; Ward, K. Relationality/territoriality: Toward a conceptualization of cities in the world. Geoforum 2010, 41, 175-184. [CrossRef]

31. Martelli, C. A Linguistic Approach to the Construction of Complex Statistical Information Systems. In Survey and Statistical Computing IV. The Impact of Technology on the Survey Process; Birks, D., Banks, R., Gerrard, L., Johnson, A.J., Khan, R., Macer, T., Wills, P., Eds.; Association for Survey Computing: New York, NY, USA, 2011; p. 185.

32. Bruner, J. Acts of Meaning; Harvard University Press: Cambridge, MA, USA, 1990.

33. Wand, Y.; Monachi, D.E.; Parsons, J.; Woo, C.C. Theoretical foundations for conceptual modelling in information systems development. Decis. Support Syst. 1995, 15, 285-304. [CrossRef]

34. Avison, D.; Fitzgerald, G. Information Systems Development: Methodologies, Techniques and Tools; McGraw Hill: New York, NY, USA, 2003.

35. Novak, J.D. Learning, Creating, and Using Knowledge: Concept Maps as Facilitative Tools in Schools and Corporations; Routledge: Abingdon-on-Thames, UK, 2010.

36. Novak, J.D.; Cañas, A.J. The Theory Underlying Concept Maps and How to Construct and Use Them. Available online: http:/ / eprint.ihmc.us/5/ (accessed on 15 June 2016).

37. Hartley, R. Conceptualizing and supporting the learning process by conceptual mapping. Smart Learn. Environ. 2014, 1, 1. [CrossRef]

38. Martin, L.G. A New Model for Adult Literacy Education: Technology-Based Concept Mapping in GED Preparation. Available online: http://newprairiepress.org/aerc/2014/papers/50 (accessed on 20 January 2017).

39. Novak, J.D.; Gowin, D.B. Learning How to Learn; Cambridge University Press: Cambridge, UK, 1984.

40. Daft, R.L.; Wiginton, J.C. Language and organization. Acad. Manag. Rev. 1979, 4, 179-191.

41. Carrington, S.; Robinson, R. A case study of inclusive school development: A journey of learning. Int. J. Incl. Educ. 2004, 8, 141-153. [CrossRef]

42. Repko, A.F. Transforming an Experimental Innovation into a Sustainable Academic Program at the University of Texas-Arlington. In The Politics of Interdisciplinary Studies: Essays on Transformations in American Undergraduate Programs; Augsburg, T., Henry, S., Eds.; McFarland: Jefferson, NC, USA, 2009.

43. Etzkowitz, H.; Ranga, M. A Triple Helix System for Knowledge-Based Regional Development: From "Spheres" to "Spaces". In Proceedings of the VIII Triple Helix Conference, Madrid, Spain, 20-22 October 2010.

44. Naidoo, R. Fields and institutional strategy: Bourdieu on the relationship between higher education, inequality and society. Br. J. Sociol. Educ. 2004, 25, 457-471. [CrossRef]

45. Munawar, B.; Rafique, H. Structuralist Analysis of the Poem "The Stone Chat" by Taufeeq Rafat in perspective of Binary Opposition. Int. J. Appl. Linguist. English Lit. 2016, 5, 122-126.

46. Blackburn, S. Oxford Dictionary of Philosophy, 2nd ed.; Oxford University Press: Oxford, UK, 2008.

47. Grenfell, M. Bourdieu and Initial Teacher Education-a post-structuralist approach. Br. Educ. Res. J. 1996, 22, 287-303. [CrossRef]

48. Edwards, R.; Usher, R. Postmodernism and Education: Different Voices, Different Worlds; Routledge: Abingdon-on-Thames, UK, 2002.

(C) 2017 by the author; licensee MDPI, Basel, Switzerland. This article is an open access article distributed under the terms and conditions of the Creative Commons Attribution (CC BY) license (http:/ / creativecommons.org/licenses/by/4.0/). 